\title{
Approach to Cognitive Impairment in Parkinson's Disease
}

\author{
Qiang Zhang ${ }^{1,2} \cdot$ Georgina M. Aldridge ${ }^{1} \cdot$ Nandakumar S. Narayanan $^{1} \cdot$ Steven W. Anderson ${ }^{1} \cdot$ Ergun Y. Uc $^{1,2}$ (D)
}

Accepted: 30 October 2020 / Published online: 17 November 2020

(C) The American Society for Experimental NeuroTherapeutics, Inc. 2020

\begin{abstract}
Cognitive dysfunction is common in Parkinson's disease (PD) and predicts poor clinical outcomes. It is associated primarily with pathologic involvement of basal forebrain cholinergic and prefrontal dopaminergic systems. Impairments in executive functions, attention, and visuospatial abilities are its hallmark features with eventual involvement of memory and other domains. Subtle symptoms in the premotor and early phases of PD progress to mild cognitive impairment (MCI) which may be present at the time of diagnosis. Eventually, a large majority of PD patients develop dementia with advancing age and longer disease duration, which is usually accompanied by immobility, hallucinations/psychosis, and dysautonomia. Dopaminergic medications and deep brain stimulation help motor dysfunction, but may have potential cognitive side effects. Central acetylcholinesterase inhibitors, and possibly memantine, provide modest and temporary symptomatic relief for dementia, although there is no evidence-based treatment for MCI. There is no proven disease-modifying treatment for cognitive impairment in PD. The symptomatic and disease-modifying role of physical exercise, cognitive training, and neuromodulation on cognitive impairment in PD is under investigation. Multidisciplinary approaches to cognitive impairment with effective treatment of comorbidities, proper rehabilitation, and maintenance of good support systems in addition to pharmaceutical treatment may improve the quality of life of the patients and caregivers.
\end{abstract}

Key Words Parkinson's disease $\cdot$ dementia $\cdot$ mild cognitive impairment $\cdot$ neuropsychology $\cdot$ cholinesterase inhibitors $\cdot$ deep brain stimulation $\cdot$ neuromodulation $\cdot$ neurorehabilitation.

$\overline{\text { Qiang Zhang and Georgina M. Aldridge contributed equally to this work. }}$ Qiang Zhang and Georgina M. Aldridge are co-first authors of this article.

Ergun Y. Uc

ergun-uc@uiowa.edu

Qiang Zhang

qiang-zhang@uiowa.edu

Georgina M. Aldridge

georgina-aldridge@uiowa.edu

Nandakumar S. Narayanan

nandakumar-narayanan@uiowa.edu

Steven W. Anderson

steven-anderson@uiowa.edu

1 Department of Neurology, Carver College of Medicine, University of Iowa, 200 Hawkins Drive-2RCP, Iowa City, Iowa 52242, USA

2 Neurology Service, Veterans Affairs Medical Center, Iowa City, Iowa, USA

\section{Introduction}

Cognitive impairment in Parkinson's disease (PD) ranges from subjective cognitive symptoms to mild cognitive impairment (MCI) with objective cognitive deficits and eventually to dementia (PDD) with progressive deficits severe enough to impair daily life [1-3]. Cognitive impairment affects important aspects of life such as occupation and driving even in early phases of PD and becomes a key predictor of nursing home placement and death later in the course [4-11]. The diagnostic criteria for evaluating MCI in PD (PD-MCI) by the International Parkinson and Movement Disorder Society stipulate gradual decline in cognitive ability that is not yet sufficient to interfere significantly with functional independence despite subtle difficulties on complex functional tasks, accompanied by one to two standard deviation (SD) reduction on cognitive test performance or significant decline on serious testing [1]. MCI is found in about $20 \%$ of PD patients at the time of diagnosis [3, 12-15]. Across all existing cases of PD, MCI is found in about $27 \%$ with a range of 19 to $38 \%$ [1], although some estimates suggest a frequency up to $60 \%$ 
[3]. The clinical profile of PD-MCI is heterogeneous with involvement of a range of cognitive domains. However, "nonamnestic, single-domain" is the most common subtype of PD-MCI [16]. It is important to identify patients with PD-MCI as this could facilitate clinical trials for therapies targeting cognitive impairment early during the disease course.

Diagnosis of PDD requires impairment in more than one cognitive domain with test performance $>2$ SD below appropriate norms, significant decline from premorbid levels, and deficits severe enough to impair daily life in social or occupational realms $[2,8]$. The point prevalence of dementia in PD is about 30 to $40 \%$, but it may eventually affect a large majority (up to $80+\%$ ) of PD patients with increasing age and disease duration $[3,17,18]$. Presence of MCI, older age, higher severity of motor symptoms, predominant gait and bulbar dysfunction, autonomic symptoms, hallucinations, limited cognitive reserve, and worsening of cognitive performance on serial testing increase the risk for significant cognitive impairment and PDD [2, 19-21]. PDD, as a late manifestation of the disease, is usually accompanied by gait and balance disorders not well responsive to dopaminergic treatment and deep brain stimulation (DBS), apathy, sleep-wake cycle problems, hallucinations/psychosis, hypophonia and dysphagia, and dysautonomia with sometimes disabling orthostatic hypotension [22]. Many of these comorbid features are due to advancing neurodegeneration, sometimes exacerbated by treatments for motor dysfunction [22]. PDD also places a strong burden on caregivers and requires multidisciplinary care with contributions from neuropsychology, psychiatry, physical therapy, occupational therapy, speech therapy, social work, primary care, and other disciplines in addition to neurology [21].

Dementia with Lewy bodies (DLB) and PDD both present with Lewy body-related neuropathological changes [23, 24]. They also have similar clinical profiles, including visual hallucinations, cognitive fluctuations, and parkinsonian motor symptoms $[23,24]$. The cognitive deficits in PD, PDD, and DLB overlap with each other and are distinct from other neurodegenerative diseases, such as Alzheimer's disease (AD) $[25,26]$. Although some studies have reported differences in neuropsychological profile between these diseases, general consensus is they represent a spectrum of disease with a similar pattern of deficits, including impairment in executive, attention, visuospatial, and arousal domains [3, 23, 24]. Deficits in episodic memory and language are more characteristic of $\mathrm{AD}$, but given the overlap in proteinopathies, especially in later stages, these domains will also be discussed. In DLB, dementia usually precedes the development of parkinsonian motor symptoms. By the concensus criteria, DLB is diagnosed when dementia has developed up to 1 year after the onset of motor symptoms, whereas PDD is defined as dementia that arises in established PD with more than 1 year duration of motor symptoms [2, 25, 27].

\section{Cognitive Domains and Neurotransmitters}

Detailed mechanisms underlying the cognitive impairment in PD are not fully understood. However, it has been well established that PD patients have early cholinergic degeneration in the basal forebrain, which provides cholinergic innervations to the entire neocortex [28-30]. In addition, the abnormalities in the prefrontal dopaminergic system and other neurotransmitter systems (e.g., noradrenergic, serotoninergic) play a role [3, 31-33]. Pathology in brain regions associated with cognitive functions include Lewy bodies, Lewy neurites, coexistent Alzheimer's pathology (amyloid and tau), and ischemic changes affecting the microvasculature $[3,31]$.

When a patient with parkinsonism presents with cognitive complaints, the most useful evaluation would include a neuropsychological assessment using normative data adjusted for age and education. However, due to patient preference, availability, or insurance coverage, such an evaluation is not always immediately available. In such cases "bedside" testing can assist the neurologist or general practitioner in corroborating the history, identifying potential deficits, or revealing key changes from prior clinic visits. The Montreal Cognitive Assessment (MOCA) includes several of the bedside tests discussed below and has been validated and was recommended as screening measure in PD patients [34, 35]. Here, we discuss general cognitive domains affected in PD and related dementias, symptoms patients or families might describe, and simple tests that help explore these deficits. Detection of the specific cognitive domains involved in patient's complaints can be helpful as they may help predict improvement or worsening with medication, highlight the need for detailed neuropsychological testing if symptoms do not fit a pattern, or help the family understand the reasoning for behaviors. Finally, we explore what is known about the effects of cholinergic and dopaminergic treatment on these symptoms, given these are the most commonly used medications in PD and may differentially affect patients' symptoms.

\section{Executive Functions}

"Executive" refers to a set of higher-order abilities that guide goal-directed behavior, including planning, mental flexibility, self-control, working memory, motor sequencing, timing, and controlling attention. Executive functions generally require coordinated activity in multiple, distributed brain regions, including but not limited to the prefrontal cortex [36]. Table 1 indicates examples of executive functions, including relevant symptoms patients or their families might describe. Bedside tests of executive function are often sensitive to damage in multiple cognitive domains and thus are not necessarily specific. However, using several bedside tasks can give the examiner significant clues to the pattern of deficits. Further, watching how the patient performs the task may be more 
Table 1 Cognitive domains: clinical features, underlying pathology, response to neurotransmitter manipulation. Executive, visuospatial, and arousal are cognitive domains commonly associate with Parkinson's disease (PD) and associated dementias

\begin{tabular}{|c|c|c|c|c|c|}
\hline Cognitive domain & Relevant symptoms & Localization & $\mathrm{AChRx}$ & DARx & Bedside $(<5$ min $)$ test \\
\hline \multicolumn{6}{|l|}{ Executive } \\
\hline Planning & Trouble organizing & DL PFC $\rightarrow$ DL caudate & $\uparrow$ & $\uparrow$ & $\begin{array}{l}\text { Clock drawing, have patient describe } \\
\text { steps to plan for trip }\end{array}$ \\
\hline Cognitive flexibility & $\begin{array}{l}\text { Perseveration, difficulty } \\
\text { switching tasks }\end{array}$ & DL PFC $\rightarrow$ DL caudate & $\uparrow$ & $\uparrow$ & $\begin{array}{l}\text { Trail making test B, phonemic fluency } \\
\text { ("F" words in } 60 \mathrm{~s} \text { ) }\end{array}$ \\
\hline Motor inhibition & Driving errors & PFC to dorsal striatum & & $\uparrow$ & Go/no-go, Luria loops, Luria parapets \\
\hline Cognitive inhibition & $\begin{array}{l}\text { Impulsivity, sexual } \\
\text { disinhibition, } \\
\text { obsessions }\end{array}$ & PFC to ventral striatum & & $\downarrow$ & Swearing during phonemic fluency \\
\hline Working memory & $\begin{array}{l}\text { Forgetting reason for } \\
\text { entering room }\end{array}$ & DL PFC $\rightarrow$ DL caudate & & $\uparrow$ & $\begin{array}{l}\text { Digit span forward and in reverse, simple } \\
\text { calculations }\end{array}$ \\
\hline Motor sequencing & $\begin{array}{l}\text { Difficulty using new } \\
\text { tools }\end{array}$ & PFC to ventral striatum & & $\downarrow$ & Luria (fist-edge-palm) motor sequence \\
\hline Timing & Misjudging time & Medial PFC & & $\uparrow$ & Finger tapping \\
\hline Controlling attention & Missing road signs & DL PFC, AC & $\uparrow$ & $\uparrow$ & $\begin{array}{l}\text { Months backwards, auditory target } \\
\text { detection (tap on "A" in letter } \\
\text { sequence) }\end{array}$ \\
\hline Initiation & Procrastination of tasks & $\mathrm{PFC} \rightarrow$ striatum & & $\uparrow$ & Write a sentence (time to initiate) \\
\hline \multirow[t]{2}{*}{ Arousal } & Fluctuations, delirium & Thalamus, DMN, BF & & & Screening by history \\
\hline & Daytime sleepiness & Brainstem nuclei, BF & $\uparrow$ & $\downarrow \uparrow$ & Observation during exam \\
\hline \multicolumn{6}{|l|}{ Visuospatial } \\
\hline \multirow[t]{2}{*}{ Perceptual discrimination } & $\begin{array}{l}\text { Recognizing object in } \\
\text { fridge }\end{array}$ & $\begin{array}{l}\text { Occipitotemporal, } \\
\text { ventral "what" } \\
\text { pathway }\end{array}$ & $\sim$ & $\uparrow$ & Overlapping figures \\
\hline & Illusions, hallucinations & Multiple, thalamus & $\uparrow$ & $\downarrow$ & Noise pareidolia task \\
\hline $\begin{array}{l}\text { Face } \\
\text { recognition/discrimination }\end{array}$ & $\begin{array}{l}\text { Confusion in social } \\
\text { settings }\end{array}$ & Right fusiform, PFC & & $\sim$ & Identify famous faces \\
\hline Emotion recognition & Interpersonal difficulties & PFC, AC, amygdala, BG & & $\downarrow$ & Examiner mimes emotional faces \\
\hline Spatial orientation & Getting lost & P. parietal to DL caudate & & $\sim$ & Describe route home \\
\hline Visual construction & $\begin{array}{l}\text { Trouble cooking or } \\
\text { making minor repairs }\end{array}$ & $\begin{array}{l}\text { Parietal-occipital, dorsal } \\
\text { "where" pathway }\end{array}$ & & $\sim$ & Copy figure \\
\hline Visual memory & Losing wallet, keys & Inferior temporal, V. caudate & & $\downarrow$ & Draw figure from memory \\
\hline Episodic memory* & $\begin{array}{l}\text { Forgetting conversations, } \\
\text { events }\end{array}$ & $\begin{array}{l}\text { Limbic/HPC (often } \\
\text { mixed pathology) }\end{array}$ & $\uparrow$ & $\downarrow \uparrow$ & $\begin{array}{l}\text { Verbal memory word list with category } \\
\text { and multiple-choice cues, orientation }\end{array}$ \\
\hline Language* & $\begin{array}{l}\text { Expressive or receptive } \\
\text { aphasia }\end{array}$ & $\begin{array}{l}\text { Left frontal/parietal } \\
\text { (often mixed pathology) }\end{array}$ & & & $\begin{array}{l}\text { Noun naming, simple commands, } \\
\text { category fluency (animals in } 60 \mathrm{~s} \text { ) }\end{array}$ \\
\hline
\end{tabular}

Ach = acetylcholine; $\mathrm{AC}=$ anterior cingulate $\mathrm{BF}=$ basal forebrain $; \mathrm{BG}=$ basal ganglia; $\mathrm{Da}=$ dopamine; $\mathrm{DL}=$ dorsolateral; $\mathrm{DMN}=$ default mode network; HPC = hippocampal; $\mathrm{PFC}=$ prefrontal cortex $\mathrm{P}=$ posterior; $\mathrm{Rx}=$ treatment; $\mathrm{V}=$ ventral

* Some patients may also experience deficits in other areas, including episodic memory and language, but deficits in these areas may indicate overlapping pathology with other proteinopathies, including amyloid, tau, and TDP-43. In general, identification of the specific pattern of deficits is best quantified with neuropsychological testing using age and education-adjusted normative data. However, these cognitive domains can be screened for by asking about potentially relevant symptoms (column 2) and using short bedside screening tests (column 6). Importantly, poor performance may be due to deficits in multiple cognitive domains. For example, phonemic fluency may be deficient due to difficulty with executive dysfunction or a language deficit. Comparing performance on several tests (for example phonemic to category fluency) may help distinguish the more significant deficit. Notably, cognitive symptoms and performance on cognitive tasks respond differently to cholinergic [37-40] and dopaminergic [40-57] therapies commonly used in PD. Up arrows indicate that at doses used clinically; there is some evidence for improvement in symptoms in PD patients, and down arrows indicate worsening in symptoms. Up-down arrows indicate the medication has an effect, but the direction of change is dependent on the stage of the disease or dose. $\sim$ indicates no evidence for a change. See text for further details 
important than the overall score. For example, having the patient draw a clock can demonstrate deficits in planning (the patient starts at one side with poor spacing) or visuospatial abnormalities (the patient places the 12, 3, 6, and 9 first, but in abnormal locations). Clock drawings in PD and related dementias are often different from patients with $\mathrm{AD}$ or mixed dementias, who may make errors reflecting loss of semantic knowledge (not understanding the concept of clock, therefore putting too many numbers or other similar conceptual errors) [58]. Asking the patient to recite months of the year backwards or simple mathematical calculations can be used very quickly to asses attention, which affects most other tasks and thus should be taken into consideration when evaluating performance [59]. Self-control is also considered an executive function, as the prefrontal cortex and basal ganglia circuit help balance action with inhibition of action [60]. A bedside go/nogo task (for example, as available from the Frontal Assessment Battery [61]) can help elicit evidence of motor impulsiveness, but an observant examiner may also see evidence for motor impulsiveness during an auditory target detection test of attention (e.g., tapping for "As" in a serial list of letters, as available as part of the MOCA [62]. Luria loops or written alternating sequencing (Luria parapets) can detect evidence of perseveration if the patient fails to stop the sequence $[63,64]$. However, it is important to note that cognitive testing for impulsivity differs significantly from impulse-control disorders, and thus asking family about symptoms is essential [65]. Multiple cognitive function tasks that are abnormal in PD, including those aimed at executive functions (set-shifting tasks) as well as nonexecutive functions (visuospatial tasks) correlate with risk for developing impulse-control disorders, but the underlying cause remains under investigation [66].

In general, medications that boost cholinergic signaling tend to improve executive functions, both in Parkinsonrelated disorders as well as in other neurodegenerative diseases. Improvement in executive functions may account for some of the benefit seen in both $\mathrm{PD}$ and $\mathrm{AD}$ patients on composite measures. There is evidence, for example, that attention, rather than episodic memory, is improved in AD with treatment with cholinesterase inhibitors [67]. Although most clinical trials use composite scores of cognition, there is evidence that clock drawing, phonemic fluency and tests of attention improve with cholinesterase inhibitors in PD-related dementias [37]. Symptoms of impulsivity, such as impulse purchases, gambling, sexual disinhibition, and obsessions, are varied and have multiple etiologies. Thus, response to medications cannot always be predicted and a patient and family-informed treatment trial may be necessary to determine individual response. The use of cholinesterase inhibitors in patients with sexually inappropriate behaviors has not been studied in randomized clinical trials, but a few case studies in $\mathrm{AD}$ suggest a mixed response including the potential for worsening of behaviors $[68,69]$.
The effect of dopaminergic medications on executive function has been studied in detail, but the results vary depending on the stage and severity of the disease, the dose of the medication used, and the specific portion of the task being examined [70]. It has been postulated that dopaminergic medications may improve performance on dorsal caudate-related tasks, but worsen ventral striatum-related tasks, due to uneven dopaminergic deficits between these regions [41, 71, 72]. There is some evidence that working memory, planning, and set shifting (behavioral flexibility) improve in patients taking levodopa in some situations, but the effect follows a "U"shaped curve, and further, is dependent on the context of the task, including distractors [42-44]. One study, for example, showed patients naïve to dopaminergic medication improve in tests of executive function, whereas increases in dosing in those treated chronically may actually worsen executive function [70]. Impulse-control disorders, including pathological gambling and hypersexuality are associated with higher doses of levodopa and dopamine agonists [73], but a detailed investigation and discussion with the individual patient is required as these psychiatric symptoms are often multi-factorial. Further, motor inhibition (decreased motor impulsiveness) may actually increase in patients treated with dopaminergic medications, suggesting these domains may be modulated in different ways $[45,46]$.

\section{Arousal}

Disorders of arousal are included as associated clinical features in PDD and one of the core features in DLB [2, 27]. There are multiple proposed etiologies for fluctuations of arousal, including known abnormalities in sleep and circadian rhythm, as well as potential differences in the thalamus and default mode network [74, 75]. Symptoms include daytime sleepiness, sensitivity to delirium, and significant fluctuations in cognition over minutes to days that can be severe enough to be mistaken for stroke or seizure. Arousal also overlaps considerable with proclivity for hallucinations and deficits and fluctuation in attention. Although there is no specific bedside test for fluctuations, it may be possible to note general changes in arousal, especially excessive daytime sleepiness, over the course of the exam. Comparing performance over several visits may help elucidate fluctuations. Simple screening questions during the history, such as the four questions used for the "dementia cognitive fluctuation scale" may help assess fluctuations in patients [76]. Interestingly, fluctuations in cognition and fluctuations in alertness (arousal) may vary independently, which may explain some of the difficulty in studying these symptoms [76]. Importantly, a patient who presents with a severe fluctuation in cognition or alertness should be screened for causes of altered mental status (infection, seizure, polypharmacy/medication effect, metabolic causes, etc.), 
especially if the fluctuation is out of proportion to prior episodes. One or more triggering etiologies may be found and corrected.

Despite the importance of these symptoms to patients and utilization of healthcare resources, fluctuations as outcome measures were not included in most early studies or clinical trials that evaluated response to acetylcholinesterase inhibitors [77]. Trials of cholinesterase inhibitors to treat delirium in the general hospital setting, including postoperatively, have been negative $[78,79]$. To our knowledge, randomized studies focusing on hospitalized PD patients have not been done. Thus, it is unknown if acetylcholinesterase inhibitors improve fluctuations or sensitivity to delirium in PD patients.

Although fluctuations have not been systematically evaluated, there is evidence that dopaminergic medications have a dose-dependent effect on daytime sleepiness/alertness, with low doses of both dopamine agonists and levodopa causing increased sleepiness, whereas high doses of levodopa promoted wakefulness [47]. These paradoxical responses may be important when counseling patients on side effects and trade-offs of treating motor and cognitive symptoms.

Bedside testing of cognition and attention can be done quickly during the physical exam with just a few selected tests, which is especially useful for patients unable or unwilling to sit through longer testing. For the detection of worsening over time, comparison of the patient's performance to their own performance during prior clinic visits helps decrease the influence of education and age. Keeping copies of past tests, such as clocks and copied figures provides an easy and accurate method to track performance overtime. Because cognitive fluctuations play such an important role in PD and related dementias, worsening and even striking improvement can often be seen between visits even in simple tasks such as the clock draw, making frequent serial testing more useful than a single snapshot test.

\section{Visuospatial Abilities}

Deficits in visuospatial function are listed in the diagnostic criteria of both PDD and DLB [2, 27]. Deficits throughout the visual system, including the cornea, retina, eyelids, and nerves, and cerebrum may contribute to visual disturbance in PD and should be considered, but are beyond the scope of this review [4, 80]. Visuospatial domains specific to cognition include perceptual discrimination, facial recognition, emotional recognition, spatial orientation, visual construction, and visual memory. Hallucinations are a positive symptom most often presenting in the visual domain in PDD and DLB. Although there is correlation between some visual deficits and hallucinations, it is unclear if hallucinations are driven by similar mechanisms [81]. Illusions and visual hallucinations are hallmarks of PD and related dementias and can occur early in the course of the disease, including before the onset of dementia. Based on a brain bank study, the absence of visual hallucinations or illusions during the clinical course may indicate an incorrect diagnosis of synucleinopathy [82]. Thus, screening by history and exam can be relevant for diagnosis and treatment, and illusions and hallucinations may occur before the onset of other cognitive symptoms.

Evidence for a propensity for illusions and hallucinations can be tested at bedside by asking the patient if they see faces in a random noise image (noise pareidolia task) [59]. Although the published task uses 40 images, a bedside approach with a single ambiguous image might be useful. However, as with many bedside tests, clinical correlation and interpretation is required given the lack of standardization. Similarly, for testing visual construction and visual memory, the Rey-Osterrieth complex figure has been validated in PD, but requires a specific and detailed scoring system [83]. Given the complexity and time required for this complex figure, for bedside testing, a simpler figure such as a geometric doodle could be utilized. As with the clock draw, deficits in planning versus visuospatial abnormalities can often be distinguished by watching the patient complete the task.

Based on a recent meta-analysis, there is no evidence of improvement in visuospatial function in PD-related dementias using cholinesterase inhibitors in recent clinical trials [38]. However, only three of the included clinical trials reported tests of visuospatial function separately and none used overlapping tests. Interestingly, use of cholinergic drugs in healthy controls has been shown to enhance aspects of visual function, such as detecting a target versus a distractor [84]. However, this may relate to visual attention, which was not tested in the former trials. In contrast, there is evidence that visual hallucinations are responsive to cholinesterase inhibitors. For example, a trial of the effect of donepezil in DLB patients showed significant improvement in visual hallucinations [85]. A small case series also supports the use of cholinesterase inhibitors for treatment of visual hallucinations [39]. It has long been accepted that dopaminergic medications, and especially dopamine agonists, are associated with worsening or appearance of visual hallucinations in some patients [86]. However, although the medication itself may worsen the hallucinations, prospective data suggests that time to hallucination onset is unlikely to be influenced by the dopaminergic regimen used, but rather by underlying factors of the disease itself [43].

Emotion recognition is impaired in PD even in patients without cognitive impairment [87]. Processing of emotion in faces is complex. Involved regions of brain include prefrontal cortex, cingulate, amygdala, and basal ganglia [87]. Interestingly, identifying negative emotions (anger, fear, etc.) has been shown to be more impaired than positive emotions [88]. A recent meta-analysis specifically addressed the effect of patients on and off dopaminergic medications, finding evidence that the social recognition deficit is more severe in patients who are currently on their dopaminergic medications, rather than holding them [88]. 
Patient's with PD also show impairments in visual recognition of faces, and this may be secondary to impaired discrimination and processing [89]. Facial recognition is processed in part in the fusiform face area [90]. Some studies have shown memory for faces can be specifically impaired in PD when memory for words is not, and this may be due to impaired configural processing (processing the whole of the face rather than its features) [91]. The effect of dopaminergic medications of facial discrimination has been examined in a few studies, which did not show evidence of changes when patients were on medication $[48,49]$.

\section{Episodic Memory}

Compared with patients with $\mathrm{AD}$, deficits in episodic memory in PD-related dementias are typically mild and present later in the course of the disease [2, 27]. However, compared with controls, PD patients do exhibit some variable deficits in memory. Specifically, in the absence of supplemental dopamine, one study found memory encoding is normal in PD patients, but retrieval is impaired [92]. This follows the generally accepted view that patients with PD have intact encoding, whereas retrieval, which utilizes executive functions, can be deficient. Memory deficits can be screened for at the bedside with simple word lists. Improvement with cues (category and then multiple-choice) is more indicative of retrieval errors associated with PD dementia, rather than encoding deficits, which are more commonly associated with hippocampal atrophy and overlapping amyloid/tau pathology. Interestingly, the same study described above found that dopaminergic treatment actually impaired encoding in PD patients, but improved retrieval [42]. The task dependent and dose-dependent effects of dopamine may play a role in the variability seen in cognition in PD and related dementias. For cholinergic modulation, at least one clinical trial has shown evidence for improvement in auditory word list memory with a cholinesterase inhibitory (donepezil) in PD, but further studies are necessary to separate effects of encoding and retrieval [40].

\section{Language}

Deficits in language usually indicate overlapping pathology with other neurodegenerative conditions or vascular dementia. Diagnostic criteria for PDD suggest that core functions in language should be largely preserved [2]. However, given that more than half of patients with PD-related dementia have comorbid amyloid pathology [27, 93], screening for these deficits is important for prognosis and treatment. Screening for language deficits is a common part of the general neurologic exam, including naming nouns, repetition, and following commands. Adding a test of category fluency (for example, naming animals in $60 \mathrm{~s}$ ) can indicate a deficit in language when paired with corroborating evidence, such as symptomatic complaints of word-finding and paraphasic errors.

A recent meta-analysis of treatment with cholinesterase inhibitors suggested there was improvement in the language domain in Parkinson's disease dementia [38]. However, tests that are sensitive to executive dysfunction were included, making it difficult to draw any conclusions. For example, the tests of language included Stroop testing and letter (phonemic) fluency, both of which are strongly associated with executive functions. Thus, it is not clear that cholinergic medications specifically improve language in PD, but additional studies are necessary to better address these questions.

\section{Treatment of Cognitive Impairment in PD}

\section{Treatment of Risk Factors and Comorbidities}

There is no disease-modifying therapy for PD, PDD, or DLB; however, a recent systemic meta-analysis identified nine risk factors that are associated with increased risk of cognitive impairment in PD [24, 94, 95]. These risk factors include PD-related symptoms (postural instability/gait disorder, hallucinations, and orthostatic hypotension), comorbidities (cerebrovascular disease, diabetes mellitus, obesity, and cardiac disease), and lifestyles (alcohol consumption and smoking). Importantly, several of these risk factors are potentially modifiable, including alcohol consumption, smoking, and obesity.

Evaluation for cognitive worsening should also include detailed neuroimaging to rule out structural etiologies such as stroke, chronic subdural hematoma, and neoplasm, especially if the cognitive change is abrupt or is associated with other neurological deficits [3]. It is also imperative to check for and treat reversible causes of cognitive impairment such as systemic and central nervous system infections, impaired vision or hearing, metabolic abnormalities (e.g., hypothyroidism), and nutritional deficiencies (e.g., vitamin $\mathrm{B}_{12}$ deficiency) [3].

Factors that can exacerbate cognitive impairment should also be evaluated and addressed. These include polypharmacy, psychiatric disorders, and sleep disorders $[23,24]$. Psychoactive medications should be avoided if possible. When a treatment is necessary, medications with the least adverse effects on cognition should be considered. For example, paroxetine is highly effective in the management of depression in PD. However, comparing to other depression medications, paroxetine has the worst anticholinergic profile and therefore should be avoided in PD patients with cognitive impairment [96, 97]. Anticholinergic medications are known to have the potential for acute worsening of cognitive function. In addition, some evidence suggests an association with the development of dementia [98]. Medications with direct anticholinergic as well as indirect anticholinergic properties 
should be screened for at every visit. Oxybutynin, an anticholinergic medications used for treatment of overactive bladder, should not be prescribed as first line in patients with PD, as it has been shown to distribute to the CNS and cause cognitive impairment in some patients [99]. Alternatives exist, including anticholinergics with less CNS distribution and beta- 3 agonists (mirabegron) [100]. Additionally, nonprescription medications should be screened for, such as over the counter sleep aids containing diphenhydramine, which also have anticholinergic properties [101]. Patient's should be counseled to discontinue these products, and instead, institute nonpharmacological sleep hygiene approaches or pharmacological sleep aide approaches that also target comorbid symptoms such as hallucinations, psychosis, or depression [102].

Psychiatric disorders and sleep disorders can themselves provoke and exacerbate cognitive impairment. Therefore, psychiatric disorders, including depression and anxiety, and sleep disorders, in particular obstructive sleep apnea, should be evaluated and treated using a multidisciplinary approach when necessary.

\section{Pharmaceutical Management of PDD}

Detailed mechanisms underlying the cognitive impairment in PD are not fully understood. However, it has been well established that PD patients have early cholinergic degeneration in the basal forebrain, which provides cholinergic innervations to the entire neocortex $[28,29]$. Therefore, acetylcholinesterase inhibitors (AChEI) have been extensively evaluated for the treatment of PDD. Currently, only one drug, rivastigmine, has been approved by the food and drug administration (FDA) for the treatment of cognitive impairment in PDD. Table 2 shows medications used in PDD.
Rivastigmine is an AChEI, and one of the three AChEIs currently approved by the FDA for the treatment of cognitive symptoms in $\mathrm{AD}$. It is unique in that it inhibits both acetylcholinesterase and butrylcholinesterase, which has been suggested as a potential reason for its efficacy [104]. Rivastigmine was determined to be efficacious in a 24-week, double-blind, and placebo-controlled trial of 541 patients with mild to moderate PDD [37]. Study drug doses were increased during a 16-week dose-escalation period with the highest well-tolerated dose for each patient being maintained for the rest of the study. The mean dose of rivastigmine was $8.6 \mathrm{mg} /$ day at the end of the dose-escalation phase. Primary efficacy variables included the scores for the Alzheimer Disease Assessment Scale-Cognitive Subscale (ADAS-cog) and the Alzheimer's Disease Cooperative Study-Clinician's Global Impression of Change (ADCS-CGIC). Secondary outcomes comprised the Alzheimer's Disease Cooperative StudyActivities of Daily Living (ADCS-ADL), the 10-item neuropsychiatric inventory (NPI), the mini-mental state exam (MMSE), the Cognitive Drug Research (CDR) Computerized Assessment System, the Delis-Kaplan Executive Function System (D-KEFS) Verbal Fluency Test, and the 10-point Clock Drawing Test. After 24 weeks of treatment, the rivastigmine group showed a mean improvement of 2.1 points on the ADAS-cog, compared to a 0.7-point decline in the placebo group. Clinical improvement on the ADCSCGIC was observed in $19.8 \%$ in the rivastigmine arm compared to $14.5 \%$ in the placebo arm $(p=0.007)$. Furthermore, clinically meaningful worsening on ADCS-CGIC was observed in $13 \%$ in the rivastigmine group and $23.1 \%$ in the placebo group $(p=0.007)$. Moreover, rivastigmine provided significant benefit over placebo with respect to all secondary efficacy variables. Of note, significantly more patients from the rivastigmine group experienced nausea, vomiting, tremor,

Table 2 Pharmaceutical management of Parkinson's disease dementia (PDD)

\begin{tabular}{|c|c|c|}
\hline Drug & Dose & Comments \\
\hline Rivastigmine (capsule) & $1.5-6 \mathrm{mg}$ twice daily & $\begin{array}{l}\text { Acetylcholinesterase inhibitor (AChEI), only FDA-approved medication for } \\
\text { cognitive symptoms of PDD. Common side effects include nausea, vomiting, } \\
\text { and tremor. Rare bradycardia }\end{array}$ \\
\hline Rivastigmine (Patch) & $4.6-13.3 \mathrm{mg}$ daily & $\begin{array}{l}\text { Transdermal formulation, improved side effect profile, less nausea, vomiting, and } \\
\text { tremor compared to oral formulation }\end{array}$ \\
\hline Donepezil & 5-10 mg* daily & $\begin{array}{l}\text { AChEI, FDA approved for Alzheimer's disease but not PDD. Reasonable to } \\
\text { consider in PDD. Similar side effect profile as rivastigmine }\end{array}$ \\
\hline $\begin{array}{l}\text { Galantamine } \\
\text { Galantamine extended release (ER) }\end{array}$ & $\begin{array}{l}4-12 \mathrm{mg} \text { twice daily } \\
8-24 \mathrm{mg} \text { daily }\end{array}$ & $\begin{array}{l}\text { AChEI, FDA approved for Alzheimer's disease but not PDD. Reasonable to consider } \\
\text { in PDD. Similar side effect profile as rivastigmine }\end{array}$ \\
\hline $\begin{array}{l}\text { Memantine } \\
\text { Memantine extended release (ER) }\end{array}$ & $\begin{array}{l}5-10 \mathrm{mg} \text { twice daily } \\
7-28 \mathrm{mg} \text { daily }\end{array}$ & $\begin{array}{l}N \text {-Methyl-D-aspartate (NMDA) receptor antagonist, FDA approved for moderate } \\
\text { to severe Alzheimer's disease, but not for PDD. Evidence of efficacy not established } \\
\text { in PDD, though widely prescribed partly due to tolerability. Occasional worsening } \\
\text { of hallucinations reported }\end{array}$ \\
\hline
\end{tabular}

*23 mg/day of donepezil has been studied in moderate to severe Alzheimer's disease and was found to have greater efficacy but increased side effects [103]. This dose has not been studied in PDD 
and dizziness. In another 76-week, open-label study, 583 PDD patients were randomized to either oral or transdermal formulation of rivastigmine, to evaluate the long-term safety [105]. More tremor (24.5\% vs. 9.7\%), nausea ( $40.5 \%$ vs. $8.3 \%)$, and vomiting (15.3\% vs. $2.8 \%)$ were reported in the capsule group, whereas more application site erythema $(13.9 \%$ vs. $0 \%$ ) was reported in the patch group. This study supports the long-term safety of rivastigmine in PDD, and no new or unexpected safety issues emerged. Of note, in addition to cognitive impairment, rivastigmine may also improve apathy in PD [106]. In a 6-month, double-blind, placebo-controlled, and randomized clinical trial, among $30 \mathrm{PD}$ patients without dementia or depression, but with moderate to severe apathy, rivastigmine transdermal patch significantly improved the Lille Apathy Rating Scale (LARS).

Donepezil is an FDA-approved medication for the treatment of cognitive symptoms in AD. A 24-week, double-blind, placebo-controlled, and randomized clinical trial of 550 PDD patients was performed to evaluate the efficacy of donepezil on cognitive impairment in PDD [107]. Coprimary end points were the ADAS-cog and Clinician's Interview-Based Impression of Change plus caregiver input (CIBIC+). Secondary end points included executive function, attention, activities of daily living (ADLs), and behavioral symptoms. ADAS-cog changes from baseline to end point were not significant for donepezil. The 10-mg group, but not the 5-mg group, had significantly better CIBIC+ scores compared with placebo. Secondary end points including the Mini-Mental State Exam, Delis-Kaplan Executive Function System and Brief Test of Attention showed significant benefit for both donepezil doses. There were no significant differences in ADLs or behavioral symptoms. In addition to this trial, 3 clinical trials (two cross-over, randomized controlled trials, and one placebo-controlled, randomized trial) with smaller numbers of patients (ranging from 14 to 22) were performed to evaluate the efficacy of donepezil in PDD. Though one study was positive for one of the two primary endpoints [108], the other two studies had negative results for the primary endpoints $[109,110]$. In another randomized, doubleblind, placebo-controlled study among 140 DLB patients, donepezil improved MMSE, CIBIC+, behavioral measures, and caregiver burden [111].

Galantamine is another AChEI approved by the FDA for AD treatment. Only one open-label trial evaluated the efficacy of galantamine in PDD. This was a 24-week, open-label, and randomized controlled trial of 41 patients with PDD. A primary outcome was not specified in this study. Comparing to the placebo group, galantamine improved scores on all measures of cognitive impairment in this study, including MMSE, the ADAS-Cog, the Frontal Assessment Battery (FAB), the Clock Drawing Test, the NPI, the Disability Assessment for Dementia (DAD), and assessment of distress of the relatives.
Despite these mixed results, a meta-analysis study has suggested that AChEIs improve global impression of efficacy as well as objective cognitive function [112]. Therefore, in addition to rivastigmine, it is reasonable to consider donepezil and galantamine in PDD management. A recent study analyzed medical records from 268,407 Medicare beneficiaries with PD, and identified 73,093 (27.2\%) patients who were prescribed antidementia medications. Of these, $63.0 \%$ were taking donepezil, $26.4 \%$ were taking rivastigmine, $2.9 \%$ were taking galantamine, and $41.8 \%$ were taking memantine [113].

Memantine is an $N$-methyl-D-aspartate (NMDA) receptor antagonist and an FDA-approved medication for the management of cognitive symptoms in moderate to severe AD. Three double-blind, placebo-controlled, and randomized trials have evaluated the efficacy of memantine in PDD [114], two of which also included patients with DLB $[115,116]$. The first study included 25 PDD patients [114]. After 16 weeks of treatment, no significant difference was noted between the memantine and placebo group on the primary outcome: dementia rating scale (DRS). The second study included 72 patients with PDD or DLB [115]. After 24 weeks of treatment, patients in the memantine group had better ADCS-CGIC scores (primary outcome) than those taking placebo, however, with the exception of improved speed on attentional tasks in the memantine group, there were no significant differences between the groups in secondary outcome measures. A third study included 199 patients with PDD or DLB [116]. After 24 weeks of treatment, there were no significant differences between the memantine group and the placebo group on CGIC, NPI, cognitive testing, activities of daily living, and Zarit caregiver burden scores. However, subgroup analysis indicated that DLB patients who were treated with memantine had significantly higher sores on CGIC and NPI compared to the placebo group. Because of these conflicting results, the evidence to support the efficacy of memantine is generally considered insufficient. However, as discussed earlier, one study indicated that $41.8 \%$ of all PD patients taking antidementia medications were prescribed memantine. This is partly due to the very limited options of treatments and the excellent side effect profile of memantine, with the exception of reports of worsening of hallucinations with memantine in PDD and DLB [117, 118].

In summary, all $4 \mathrm{FDA}$-approved medications for $\mathrm{AD}$ have been evaluated in PDD treatment. Although only rivastigmine has been approved by the FDA for the treatment of PDD, it is reasonable to consider donepezil and galantamine in PDD despite the equivocal evidence from clinical trials. Side effects of AChEIs include nausea/vomiting and worsened tremor, which might be lessened by the transdermal formulation. On the other hand, due to the conflicting results, currently, there is insufficient evidence to determine the efficacy of memantine in PDD. Despite this, memantine has been widely prescribed among PDD patients, partly due to its tolerability. 


\section{Clinical Trials Targeting PD-MCI}

Currently, no medication has been approved by the FDA for the treatment of cognitive symptoms in PD-MCI. However, rivastigmine, rasagiline (a monoamine oxidase $\mathrm{B}$ (MAO-B) inhibitor), and atomoxetine (a norepinephrine (NE) reuptake inhibitor) have been evaluated for the treatment of PD-MCI.

Rivastigmine. A 24-week, cross-over, randomized, doubleblind, and placebo-controlled trial with 28 PD-MCI patients showed no significant difference between the rivastigmine transdermal patch and the placebo arms on the primary outcome of ADCS-CGIC, although a trend favoring rivastigmine was noted $(p=0.096)$ [119]. The Everyday Cognition Battery (ECB) was significantly improved in the rivastigmine phase, but no significant differences were noted with other secondary outcomes.

Rasagiline, MAO-B inhibitor, has been approved by the FDA for motor symptoms of PD [120]. Two randomized, double-blind, and placebo-controlled trials evaluated the efficacy of rasagiline in PD-MCI. In the first trial of 55 patients with PD-MCI, after 3 months of treatment, the rasagiline group had significant better performance in the digit spanbackward score, the verbal fluency total score, and the attentional $Z$ score [121]. However, in another study of 170 patients with PD-MCI, after 24 weeks of treatment, there were no significant difference between the rasagiline and the placebo group on the primary outcome: Scales for Outcomes of Parkinson's Disease-Cognition scores [122]. There were also no differences on secondary measures of cognitive impairment.

Atomoxetine is an NE reuptake inhibitor. It can increase the levels of NE and dopamine in certain parts of the brain such as the prefrontal cortex. Atomoxetine has been approved by the FDA for the treatment of attention-deficit hyperactivity disorder (ADHD). In a randomized, double-blind, and placebocontrolled trial of 30 PD-MCI patients, after 10 weeks of treatment, no significant difference was noted between the atomoxetine group and the placebo group on the primary outcome: global statistical test (standardized tests of attention, working memory, processing speed, and set shifting) [123]. However, comparing to the placebo group, atomoxetine treatment was associated with significant improvement in subjective measures of attention and impulsivity (Conners Adult Attention Deficit Hyperactivity Disorder Rating Scale).

\section{Neuromodulation for Cognitive Impairment in PD}

Neuromodulation refers to the alteration of nervous system activity through an external stimulus such as electrical pulses [124]. Neuromodulation via deep brain stimulation (DBS) is highly effective for motor symptoms of Parkinson's disease $[125,126]$. This effort was based on decades of sustained and principled investigation, followed by multiple high-quality clinical trials. Unfortunately, far less is known about the basic pathophysiology of cognitive symptoms of Parkinson's disease including the key circuit nodes that malfunction in PD patients with cognitive dysfunction. However, the potential for current and emerging neuromodulation techniques to modulate these symptoms is palpable. We will discuss neuromodulation technologies that have been shown to modulate cognition in humans, and discuss how these might be applicable to PD.

First, DBS for motor symptoms of PD targets two primary sites: the globus pallidus internal segment and the subthalamic nucleus (STN). The STN is a densely packed and topographically organized nucleus that receives inputs from basal ganglia that are putatively involved in cognitive operations [127]. In addition, the STN receives monosynaptic input from across the frontal cortex (Fig. 1, upper panel), including from prefrontal regions that are directly involved in cognitive operations such as working memory, attention, inhibitory control, timing, attention, and language [133, 134]. Critically, STNDBS can often have cognitive side effects and can transiently impact cognitive functions such as verbal fluency $[135,136]$. These data suggest that current spread from DBS electrodes
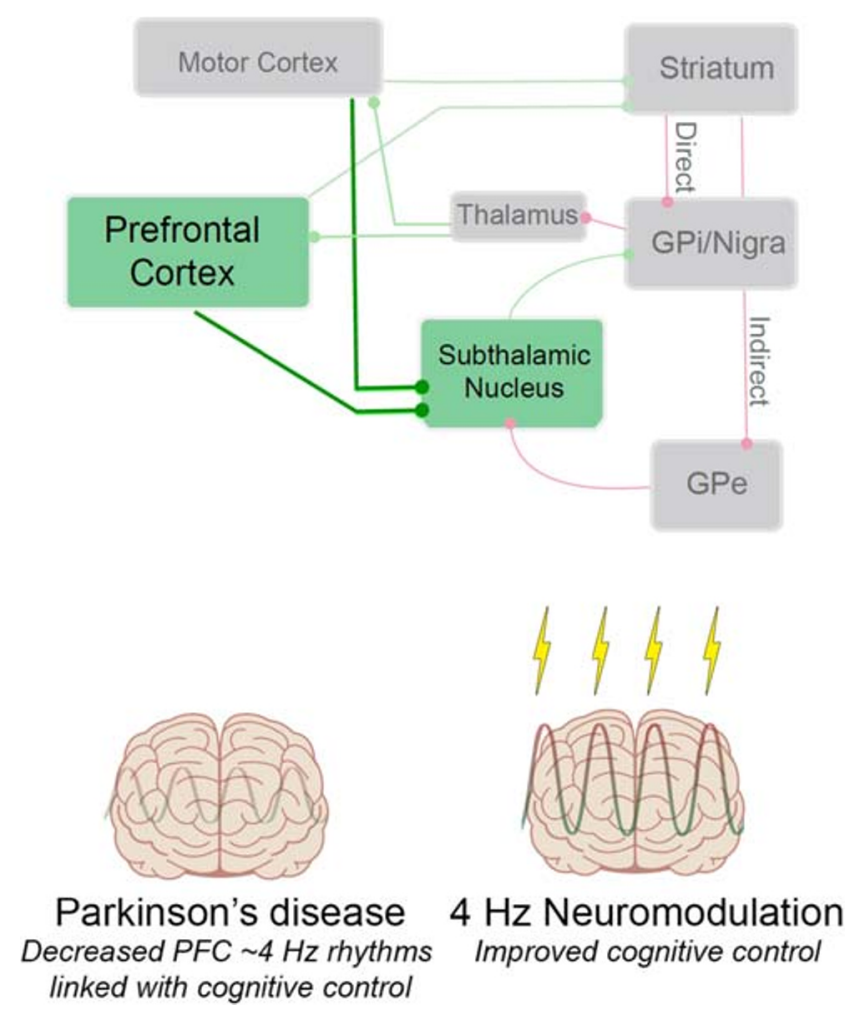

Fig. 1 Upper panel: cortico-basal ganglia circuits involved in cognitive control. The prefrontal cortex or subthalamic nucleus could be targets for future neuromodulation aimed at improving cognition in Parkinson's disease. Lower panel: work by Narayanan's group suggests that PD patients have decreased prefrontal $\sim 4 \mathrm{~Hz}$ rhythms linked with cognitive control and that $4 \mathrm{~Hz}$ neuromodulation via STN-DBS or tDCS has the potential to boost these rhythms and improve cognitive control. See references [128-132] 
targeting the dorsomedial motor regions of the STN have the potential to impact cognitive function. Of note, DBS targeting other sites (such as the nucleus basalis of Meynert) have been attempted for cognitive function in PDD [137]. Other sites, such as the fornix are currently considered as targets for cognitive symptoms of other neurodegenerative diseases such as AD [138].

STN-DBS for motor symptoms is typically at highfrequencies $>60 \mathrm{~Hz}$, leading to an "informational lesion" in the indirect pathway. However, if STN brain stimulation can worsen cognition, then a detailed understanding of its role in cognitive operations might help elucidate how to modulate STN circuits to improve cognition. Direct recordings from the STN have reported marked modulation in $4 \mathrm{~Hz}$ electrical oscillations during cognitive control tasks such as conflictreaction-time and interval timing, and $4 \mathrm{~Hz}$ coherence with prefrontal cortical regions [128, 139, 140]. Strikingly, a small study of PD patients found that low-frequency modulation of STN-DBS can improve elementary cognitive tasks such as interval timing, with $4 \mathrm{~Hz}$ STN-DBS resulting in more prefrontal $4 \mathrm{~Hz}$ power and more accurately timed responses (Fig. 1, lower panel) [128]. This finding was supported by earlier findings that STN-DBS at $10 \mathrm{~Hz}$ could modulate interval timing tasks, and independently replicated by work showing that $5 \mathrm{~Hz}$ STN-DBS could improve performance of conflictreaction-time tasks $[141,142]$. This line of evidence suggests that STN-DBS has the potential to boost cognitive performance in PD patients via the hyperdirect pathway. This idea remains to be rigorously tested in clinical trials likely involving carefully mapping of STN microanatomy vis-à-vis prefrontal hyperdirect projections.

A second technology that has great potential is noninvasive neuromodulation. This can take the form of transcranial magnetic stimulation (TMS), wherein carefully shaped magnetic fields can modulate the electrical activity of neuronal networks. TMS has been shown to modulate primary motor cortex and has been studied for motor symptoms of PD with mixed results [143]. There are encouraging preliminary results on the effect of TMS on depression and cognition in PD [144-148]. A distinct technology is transcranial stimulation with direct or alternating current (tDCS or tACS), which putatively passes low-amplitude current through the brain via scalp electrodes. Transcranial direct-current stimulation can result in working memory improvements in older adults [149]. A small study showed that tDCS can boost working memory in PD patients, although it is unclear if these effects are transient, what the underlying mechanisms are, and if such neuromodulation can transfer to real-world settings [150].

One challenge for neuromodulation is that it is unclear exactly where and how to stimulate to modulate cognitive function in PD. However, the ability to analyze ongoing brain activity and adaptively deliver brain stimulation via closedloop algorithms has the potential to make progress on this front. Closed-loop brain stimulation has used betaoscillations linked with motor dysfunction to adaptively tune DBS for motor symptoms of PD [151, 152]. Prefrontal $\sim 4 \mathrm{~Hz}$ "theta" rhythms can be associated with cognitive symptoms of PD [129-131, 153]. Advanced algorithms might harness these rhythms as a control parameter [154] to deliver highly individualized and personalized neuromodulation that is maximally effective for cognitive symptoms of PD.

\section{Neuropsychological Rehabilitation}

Every person's daily behavioral and cognitive routines are important contributors to long-term cognitive status, whether or not they have PD. When facing the challenges of cognitive impairment in the context of $\mathrm{PD}$, optimizing daily cognitivebehavioral routines is a key component of management and treatment.

Neuropsychological rehabilitation refers to the use of psychological (cognitive and behavioral) interventions directed at optimizing cognitive, emotional, and psychosocial function in PD. The interventions may include educational components, psychotherapeutic, and motivational aspects, "exercises" directed at activating or challenging specific cognitive functions, review and refinement of the key drivers of neuroplasticity underlying cognition (e.g., physical exercise, cognitive training, sleep hygiene, social engagement), and training in the use of compensatory strategies and devices.

Studies in healthy older adults suggest that physical exercise might improve cognitive function, with particular effect of aerobic exercise on executive functions [155-158]. Preliminary studies found cognitive benefits of aerobic and resistance exercise on various cognitive domains in PD [159, 160]. However, further research is needed to determine optimal type, frequency, and dosing of exercise and their efficacy using rigorous clinical trial methodology employed for pharmaceuticals in order to make evidence-based recommendations [21].

Cognitive profiles in PD are heterogeneous and change over time for individual patients, as do their environmental demands and support, requiring neuropsychological rehabilitation protocols to be individually tailored and updated over time. However, there also are common themes that apply to the treatment of most patients with PD who have cognitive difficulties. Thus, interventions involve a combination of addressing "foundation" issues that impact cognition in most patients (e.g., the negative impact of stress, poor sleep, and limited social stimulation) and addressing specific problems or goals that are important in the life of a given patient.

Targets for intervention are identified by the referring neurologist or other members of the multidisciplinary team, from the neuropsychological evaluation and from interviews with the patient and family. Collaboratively establishing explicit therapeutic goals with the patient and family is essential to 
success in this type of treatment. Compliance with cognitivebehavioral interventions is considerably more demanding than taking a medication on schedule, and it thus is essential to have "buy in" from the participants. Success is more likely when goals are tied to specific real-world activities or problems, rather than relatively abstract cognitive constructs. For a patient with episodic memory impairment, "not losing my keys" and "not missing appointments" could be very reasonable goals, whereas "improving my memory" may be elusive and require further specification.

The focus of this article is treatment of cognitive impairments, but from a neuropsychological perspective, there is no clear line of demarcation between impairments of cognition and impairments of behavior or emotion. We have no direct access to a patient's cognitive functions, except as expressed through their behavior. Further, emotional processing contributes to cognitive functions such as decision-making and allocation of attention [161]. In addition, most behavioral disorders appear to be accompanied by altered cognitive processing. For example, an impulse-control disorder is expressed via problematic behavior, but may be based on alterations in various aspects of cognition, such as perception of risk, social perception/empathy, and cost-benefit analyses.

This blending or overlap of functions is reflected in what is generally referred to as a cognitive-behavioral therapy (CBT) framework for interventions directed at both altering cognition and behavioral routines [162]. Some of the most important steps for optimizing cognitive function in PD are indirect, in that the direct target of the intervention is not cognition per se, but rather facilitation of neuroplasticity with the downstream goal of improving and/or maintaining cognitive function. As a foundation for almost all specific interventions for cognition, we begin by reviewing with the patient the common behavioral influences on neuroplasticity and PD symptomatology, including the importance of physical exercise, good sleep hygiene, adaptive stress management, and social engagement. Also included in this educational discussion of neuroplasticity is the importance of ongoing challenging cognitive stimulation, irrespective of their specific cognitive profile or other cognitive exercises that might be prescribed.

Importantly, this review is done in a CBT framework in which the provider and patient/family collaboratively problem solve in each of these domains, with the goal of optimizing the patient's daily behavioral routines and enhancing their appreciation of how important these routines can be in affecting the expression and progression of PD symptomatology. Patients often are acutely aware that their PD symptoms (including physical symptoms such as tremor and cognitive symptoms such as word-finding problems) worsen under stress and are motivated to learn behavioral methods of stress management such as progressive muscle relaxation [163]. As in all forms of rehabilitation, one role of the therapist is to be a motivator and coach, with the goal of the patient (and their family) internalizing this motivation to guide behavior once they leave the clinic.

After addressing these general influences on cognitive function, problems that arise from specific cognitive impairments can be addressed. Several studies involving patients with PD have shown that regular practice of hierarchically challenging computer games can lead to improvements in performance on measures of attention, working, memory, and speed of processing [164-167]. Outcome measures to this point have primarily been limited to laboratory measures, and generalization to improvements in real-world function is uncertain. A Cochrane Database review on the effect of cognitive training in PD-MCI and PDD found no clear evidence that cognitive training for 4 to 8 weeks improved global cognition, executive function, or visual processing, whereas there was a suggestion of benefit on attention and verbal memory. There was no evidence of differences between treatment and control groups in activities of daily living or quality of life. More robust, adequately powered studies of cognitive training were recommended [168]. However, if a patient is interested in this type of training task and has access to the requisite technology, these approaches may provide a means of strengthening specific cognitive abilities. It appears reasonable to conclude that ongoing repeated challenges in an area of cognitive weakness is likely to benefit performance within that function. The relative benefits of various types of challenges (e.g., dedicated computer programs, real-world arts and crafts, reading, puzzles, card or board games, other hobbies) are unknown, and it may be that the best advice at this point is to pursue the form of cognitive challenge that one is most likely to engage in on a regular basis.

Compensatory strategies and devices provide another method for addressing problems that arise from cognitive impairments and often are the most direct and practical approach. Among the most common methods are making lists and keeping calendars for memory problems, as well as use of medication organizers, key-finder alarms, and other reminder alarms. Relevant personal technology, such as smart phones and activity trackers, is changing rapidly and will continue to alter the use of compensatory devices. As with the other aspects of treatment, it is necessary to individually tailor compensatory strategies and devices to the needs and capabilities of individual patients.

Neuropsychological rehabilitation is an important component of the multimodal management of cognitive impairments in PD. Cognitive and behavioral interventions directly involve the patient in their own care, providing an important sense of self-control in addressing PD that may be otherwise largely absent. These interventions have the potential to significantly impact on quality of life, are relatively inexpensive, and are largely without negative side effects. 
Supplementary Information The online version contains supplementary material available at https://doi.org/10.1007/s13311-020-00963-x.

Acknowledgments Dr. Uc has received research support from the National Institutes of Health, Department of Veterans Affairs, Department of Defense, Michael J. Fox Foundation, Parkinson's Disease Foundation, and the Parkinson Study Group. Dr. Narayanan has received funding from the National Institutes of Health and the Michael J. Fox Foundation. Dr. Aldridge, Dr. Zhang, and Dr. Anderson have received funding from the National Institutes of Health. Dr. Zhang has received funding from the University of Iowa Carver College of Medicine Physician Scientist Training Pathway. Dr. Aldridge has received funding from the Williams-Cannons Faculty Fellowship and Iowa Neuroscience Institute.

Required Author Forms Disclosure forms provided by the authors are available with the online version of this article.

Supplementary Information The online version contains supplementary material available at https://doi.org/10.1007/s13311-020-00963-x.

\section{References}

1. Litvan I, Goldman JG, Troster AI, Schmand BA, Weintraub D, Petersen RC, et al. Diagnostic criteria for mild cognitive impairment in Parkinson's disease: Movement Disorder Society Task Force guidelines. Mov Disord 2012;27(3):349-56.

2. Emre M, Aarsland D, Brown R, Burn DJ, Duyckaerts C, Mizuno $\mathrm{Y}$, et al. Clinical diagnostic criteria for dementia associated with Parkinson's disease. Mov Disord 2007;22(12):1689-707; quiz 837

3. Goldman JG, Sieg E. Cognitive impairment and dementia in Parkinson disease. Clin Geriatr Med 2020;36(2):365-77.

4. Uc EY, Rizzo M, Anderson SW, Qian S, Rodnitzky RL, Dawson JD. Visual dysfunction in Parkinson disease without dementia. Neurology. 2005;65(12):1907-13.

5. Barrash J, Stillman A, Anderson SW, Uc EY, Dawson JD, Rizzo M. Prediction of driving ability with neuropsychological tests: demographic adjustments diminish accuracy. J Int Neuropsychol Soc 2010;16(4):679-86.

6. Uc EY, Rizzo M, Anderson SW, Dastrup E, Sparks JD, Dawson JD. Driving under low-contrast visibility conditions in Parkinson disease (vol 73, pg 1103, 2009). Neurology. 2010;74(7):616.

7. Uc EY, Rizzo M, Johnson AM, Emerson JL, Liu D, Mills ED, et al. Real-life driving outcomes in Parkinson disease. Neurology. 2011;76(22):1894-902.

8. Emre M, Ford PJ, Bilgic B, Uc EY. Cognitive impairment and dementia in Parkinson's disease: practical issues and management. Mov Disord 2014;29(5):663-72.

9. Uc EY, Rizzo M, O’Shea AMJ, Anderson SW, Dawson JD. Longitudinal decline of driving safety in Parkinson disease. Neurology. 2017;89(19):1951-8.

10. Schrag A, Banks P. Time of loss of employment in Parkinson's disease. Mov Disord 2006;21(11):1839-43.

11. Kempster PA, Williams DR, Selikhova M, Holton J, Revesz T, Lees AJ. Patterns of levodopa response in Parkinson's disease: a clinico-pathological study. Brain. 2007;130(Pt 8):2123-8.

12. Aarsland D, Bronnick K, Larsen JP, Tysnes OB, Alves G, Norwegian ParkWest Study G. Cognitive impairment in incident, untreated Parkinson disease: the Norwegian ParkWest study. Neurology. 2009;72(13):1121-6.
13. Aarsland D, Bronnick K, Williams-Gray C, Weintraub D, Marder $\mathrm{K}$, Kulisevsky J, et al. Mild cognitive impairment in Parkinson disease: a multicenter pooled analysis. Neurology. 2010;75(12): 1062-9.

14. Yarnall AJ, Breen DP, Duncan GW, Khoo TK, Coleman SY, Firbank MJ, et al. Characterizing mild cognitive impairment in incident Parkinson disease: the ICICLE-PD study. Neurology. 2014;82(4):308-16.

15. Broeders M, de Bie RM, Velseboer DC, Speelman JD, Muslimovic D, Schmand B. Evolution of mild cognitive impairment in Parkinson disease. Neurology. 2013;81(4):346-52.

16. Litvan I, Aarsland D, Adler CH, Goldman JG, Kulisevsky J, Mollenhauer B, et al. MDS Task Force on mild cognitive impairment in Parkinson's disease: critical review of PD-MCI. Mov Disord 2011;26(10):1814-24.

17. Aarsland D, Andersen K, Larsen JP, Lolk A, Kragh-Sorensen P. Prevalence and characteristics of dementia in Parkinson disease: an 8-year prospective study. Arch Neurol 2003;60(3):387-92.

18. Hely MA, Reid WG, Adena MA, Halliday GM, Morris JG. The Sydney multicenter study of Parkinson's disease: the inevitability of dementia at 20 years. Mov Disord 2008;23(6):837-44.

19. Hoogland J, Boel JA, de Bie RMA, Geskus RB, Schmand BA, Dalrymple-Alford JC, et al. Mild cognitive impairment as a risk factor for Parkinson's disease dementia. Mov Disord 2017;32(7): 1056-65.

20. Uc EY, McDermott MP, Marder KS, Anderson SW, Litvan I, Como PG, et al. Incidence of and risk factors for cognitive impairment in an early Parkinson disease clinical trial cohort. Neurology. 2009;73(18):1469-77.

21. Goldman JG, Vernaleo BA, Camicioli R, Dahodwala N, Dobkin $\mathrm{RD}$, Ellis T, et al. Cognitive impairment in Parkinson's disease: a report from a multidisciplinary symposium on unmet needs and future directions to maintain cognitive health. NPJ Parkinsons Dis. 2018:4:19.

22. Kalia LV, Lang AE. Parkinson's disease. Lancet. 2015;386(9996):896-912.

23. Gomperts SN. Lewy body dementias: dementia with lewy bodies and Parkinson disease dementia. Continuum (Minneap Minn). 2016;22(2 Dementia):435-63.

24. Walker Z, Possin KL, Boeve BF, Aarsland D. Lewy body dementias. Lancet. 2015;386(10004):1683-97.

25. Aldridge GM, Birnschein A, Denburg NL, Narayanan NS. Parkinson's disease dementia and dementia with Lewy bodies have similar neuropsychological profiles. Front Neurol 2018;9: 123.

26. Westervelt HJ, Bruce JM, Faust MA. Distinguishing Alzheimer's disease and dementia with Lewy bodies using cognitive and olfactory measures. Neuropsychology. 2016;30(3):304-11.

27. McKeith IG, Boeve BF, Dickson DW, Halliday G, Taylor JP, Weintraub D, et al. Diagnosis and management of dementia with Lewy bodies: fourth consensus report of the DLB Consortium. Neurology. 2017;89(1):88-100.

28. Braak H, Del Tredici K, Rub U, de Vos RA, Jansen Steur EN, Braak E. Staging of brain pathology related to sporadic Parkinson's disease. Neurobiol Aging 2003;24(2):197-211.

29. Arendt T, Bigl V, Arendt A, Tennstedt A. Loss of neurons in the nucleus basalis of Meynert in Alzheimer's disease, paralysis agitans and Korsakoff's disease. Acta Neuropathol 1983;61(2): 101-8.

30. Bohnen NI, Kaufer DI, Ivanco LS, Lopresti B, Koeppe RA, Davis $\mathrm{JG}$, et al. Cortical cholinergic function is more severely affected in parkinsonian dementia than in Alzheimer disease: an in vivo positron emission tomographic study. Arch Neurol 2003;60(12): 1745-8. 
31. Narayanan NS, Rodnitzky RL, Uc EY. Prefrontal dopamine signaling and cognitive symptoms of Parkinson's disease. Rev Neurosci 2013;24(3):267-78.

32. Kotagal V, Spino C, Bohnen NI, Koeppe R, Albin RL. Serotonin, beta-amyloid, and cognition in Parkinson disease. Ann Neurol 2018;83(5):994-1002.

33. Alberico SL, Cassell MD, Narayanan NS. The vulnerable ventral tegmental area in Parkinson's disease. Basal Ganglia 2015;5(2-3): 51-5.

34. Dalrymple-Alford JC, MacAskill MR, Nakas CT, Livingston L, Graham C, Crucian GP, et al. The MoCA: well-suited screen for cognitive impairment in Parkinson disease. Neurology. 2010;75(19):1717-25.

35. Chou KL, Amick MM, Brandt J, Camicioli R, Frei K, Gitelman D, et al. A recommended scale for cognitive screening in clinical trials of Parkinson's disease. Mov Disord 2010;25(15):2501-7.

36. Alvarez JA, Emory E. Executive function and the frontal lobes: a meta-analytic review. Neuropsychol Rev 2006;16(1):17-42.

37. Emre M, Aarsland D, Albanese A, Byrne EJ, Deuschl G, De Deyn PP, et al. Rivastigmine for dementia associated with Parkinson's disease. N Engl J Med 2004;351(24):2509-18.

38. Meng YH, Wang PP, Song YX, Wang JH. Cholinesterase inhibitors and memantine for Parkinson's disease dementia and Lewy body dementia: a meta-analysis. Exp Ther Med 2019;17(3):161124.

39. Sobow T. Parkinson's disease-related visual hallucinations unresponsive to atypical antipsychotics treated with cholinesterase inhibitors: a case series. Neurol Neurochir Pol 2007;41(3):276-9.

40. Sawada H, Oeda T, Kohsaka M, Umemura A, Tomita S, Park K, et al. Early use of donepezil against psychosis and cognitive decline in Parkinson's disease: a randomised controlled trial for 2 years. J Neurol Neurosurg Psychiatry 2018;89(12):1332-40.

41. Kwak Y, Bohnen NI, Muller ML, Dayalu P, Seidler RD. Striatal denervation pattern predicts levodopa effects on sequence learning in Parkinson's disease. J Mot Behav 2013;45(5):423-9.

42. Moustafa AA, Sherman SJ, Frank MJ. A dopaminergic basis for working memory, learning and attentional shifting in Parkinsonism. Neuropsychologia. 2008;46(13):3144-56.

43. Lewis SJ, Slabosz A, Robbins TW, Barker RA, Owen AM. Dopaminergic basis for deficits in working memory but not attentional set-shifting in Parkinson's disease. Neuropsychologia. 2005;43(6):823-32.

44. Cools R, D'Esposito M. Inverted-U-shaped dopamine actions on human working memory and cognitive control. Biol Psychiatry 2011;69(12):e113-25.

45. Yang XQ, Glizer D, Vo A, Seergobin KN, MacDonald PA. Pramipexole increases go timeouts but not no-go errors in healthy volunteers. Front Hum Neurosci 2016;10:523.

46. Yang XQ, Lauzon B, Seergobin KN, MacDonald PA. Dopaminergic therapy increases go timeouts in the go/no-go task in patients with Parkinson's disease. Front Hum Neurosci 2017;11:642

47. Bliwise DL, Trotti LM, Wilson AG, Greer SA, Wood-Siverio C, Juncos JJ, et al. Daytime alertness in Parkinson's disease: potentially dose-dependent, divergent effects by drug class. Mov Disord 2012;27(9):1118-24.

48. Anderson S, Stegemoller EL. Effects of levodopa on impairments to high-level vision in Parkinson's disease. Front Neurol 2020;11: 708.

49. Pillon B, Dubois B, Bonnet AM, Esteguy M, Guimaraes J, Vigouret JM, et al. Cognitive slowing in Parkinson's disease fails to respond to levodopa treatment: the 15-objects test. Neurology 1989;39(6):762-8.

50. Singh S, Behari M. Verbal and visual memory in patients with early Parkinson's disease: effect of levodopa. Neurol India 2006;54(1):33-7.
51. Kulisevsky J, Avila A, Barbanoj M, Antonijoan R, Berthier ML, Gironell A. Acute effects of levodopa on neuropsychological performance in stable and fluctuating Parkinson's disease patients at different levodopa plasma levels. Brain. 1996;119 ( Pt 6):2121-32.

52. Hovestadt A, De Jong GJ, Meerwaldt JD. Spatial disorientation in Parkinson's disease: no effect of levodopa substitution therapy. Neurology. 1988;38(11):1802-3.

53. Macdonald PA, Monchi O. Differential effects of dopaminergic therapies on dorsal and ventral striatum in Parkinson's disease: implications for cognitive function. Parkinsons Dis 2011;2011: 572743.

54. Costa A, Peppe A, Mazzu I, Longarzo M, Caltagirone C, Carlesimo GA. Dopamine treatment and cognitive functioning in individuals with Parkinson's disease: the "cognitive flexibility" hypothesis seems to work. Behav Neurol 2014;2014:260896.

55. Roy MA, Doiron M, Talon-Croteau J, Dupre N, Simard M. Effects of antiparkinson medication on cognition in Parkinson's disease: a systematic review. Can J Neurol Sci 2018;45(4):375404.

56. Buhusi CV, Meck WH. What makes us tick? Functional and neural mechanisms of interval timing. Nat Rev Neurosci 2005;6(10):755-65.

57. Feigin A, Ghilardi MF, Carbon M, Edwards C, Fukuda M, Dhawan V, et al. Effects of levodopa on motor sequence learning in Parkinson's disease. Neurology. 2003;60(11):1744-9.

58. Allone C, Lo Buono V, Corallo F, Bonanno L, Palmeri R, Di Lorenzo G, et al. Cognitive impairment in Parkinson's disease, Alzheimer's dementia, and vascular dementia: the role of the clock-drawing test. Psychogeriatrics. 2018;18(2):123-31.

59. O'Regan NA, Ryan DJ, Boland E, Connolly W, McGlade C, Leonard M, et al. Attention! A good bedside test for delirium? J Neurol Neurosurg Psychiatry 2014;85(10):1122-31.

60. Cox J, Witten IB. Striatal circuits for reward learning and decision-making. Nat Rev Neurosci 2019;20(8):482-94.

61. Dubois B, Slachevsky A, Litvan I, Pillon B. The FAB: a Frontal Assessment Battery at bedside. Neurology. 2000;55(11):1621-6.

62. Nasreddine ZS, Phillips NA, Bedirian V, Charbonneau S, Whitehead V, Collin I, et al. The Montreal Cognitive Assessment, MoCA: a brief screening tool for mild cognitive impairment. J Am Geriatr Soc 2005;53(4):695-9.

63. Schnider A Chapter 6 Neuropsychological testing: bedside approaches. Handbook of Clinical Neurology. 88: Elsevier; 2008. p. Pages 137-54

64. Luria AR. Higher Cortical Functions in Man. 2d ed. New York: Basic Books : Consultants Bureau; 1980. xxii, 634 p. p.

65. Hlavata P, Linhartova P, Sumec R, Filip P, Svetlak M, Balaz M, et al. Behavioral and neuroanatomical account of impulsivity in Parkinson's disease. Front Neurol 2019;10:1338.

66. Santangelo G, Raimo S, Barone P. The relationship between impulse control disorders and cognitive dysfunctions in Parkinson's disease: a meta-analysis. Neurosci Biobehav Rev 2017;77:129-47.

67. Behl P, Lanctot KL, Streiner DL, Guimont I, Black SE. Cholinesterase inhibitors slow decline in executive functions, rather than memory, in Alzheimer's disease: a 1-year observational study in the Sunnybrook dementia cohort. Curr Alzheimer Res 2006;3(2):147-56.

68. Canevelli M, Talarico G, Tosto G, Troili F, Lenzi GL, Bruno G. Rivastigmine in the treatment of hypersexuality in Alzheimer disease. Alzheimer Dis Assoc Disord 2013;27(3):287-8.

69. Lo Coco D, Cannizzaro E. Inappropriate sexual behaviors associated with donepezil treatment: a case report. J Clin Psychopharmacol 2010;30(2):221-2.

70. Murakami H, Nohara T, Shozawa H, Owan Y, Kuroda T, Yano S, et al. Effects of dopaminergic drug adjustment on executive function in different clinical stages of Parkinson's disease. Neuropsychiatr Dis Treat 2017;13:2719-26. 
71. Ceravolo R, Pagni C, Tognoni G, Bonuccelli U. The epidemiology and clinical manifestations of dysexecutive syndrome in Parkinson's disease. Front Neurol 2012;3:159.

72. Cools R, Barker RA, Sahakian BJ, Robbins TW. Mechanisms of cognitive set flexibility in Parkinson's disease. Brain. 2001;124(Pt 12):2503-12.

73. Poletti M, Logi C, Lucetti C, Del Dotto P, Baldacci F, Vergallo A, et al. A single-center, cross-sectional prevalence study of impulse control disorders in Parkinson disease: association with dopaminergic drugs. J Clin Psychopharmacol 2013;33(5):691-4.

74. Boord P, Madhyastha TM, Askren MK, Grabowski TJ. Executive attention networks show altered relationship with default mode network in PD. Neuroimage Clin 2017;13:1-8.

75. Kalaitzakis ME, Gentleman SM, Pearce RK. Disturbed sleep in Parkinson's disease: anatomical and pathological correlates. Neuropathol Appl Neurobiol 2013;39(6):644-53.

76. Lee DR, McKeith I, Mosimann U, Ghosh-Nodial A, Grayson L, Wilson B, et al. The dementia cognitive fluctuation scale, a new psychometric test for clinicians to identify cognitive fluctuations in people with dementia. Am J Geriatr Psychiatry 2014;22(9):92635 .

77. Simard M, van Reekum R. The acetylcholinesterase inhibitors for treatment of cognitive and behavioral symptoms in dementia with Lewy bodies. J Neuropsychiatr Clin Neurosci 2004;16(4):409-25.

78. Yu A, Wu S, Zhang Z, Dening T, Zhao S, Pinner G, et al. Cholinesterase inhibitors for the treatment of delirium in nonICU settings. Cochrane Database Syst Rev 2018;6:CD012494.

79. Marcantonio ER, Palihnich K, Appleton P, Davis RB. Pilot randomized trial of donepezil hydrochloride for delirium after hip fracture. J Am Geriatr Soc 2011;59 Suppl 2:S282-8.

80. Savitt J, Aouchiche R. Management of visual dysfunction in patients with Parkinson's disease. J Parkinsons Dis 2020;10(s1): S49-S56.

81. Russo M, Carrarini C, Dono F, Rispoli MG, Di Pietro M, Di Stefano $\mathrm{V}$, et al. The pharmacology of visual hallucinations in synucleinopathies. Front Pharmacol 2019;10:1379.

82. Williams DR, Lees AJ. Visual hallucinations in the diagnosis of idiopathic Parkinson's disease: a retrospective autopsy study. Lancet Neurol 2005;4(10):605-10.

83. Scarpina F, Ambiel E, Albani G, Pradotto LG, Mauro A. Utility of Boston Qualitative Scoring System for Rey-Osterrieth Complex Figure: evidence from a Parkinson's diseases sample. Neurol Sci 2016;37(10):1603-11.

84. Gratton C, Yousef S, Aarts E, Wallace DL, D'Esposito M, Silver MA. Cholinergic, but not dopaminergic or noradrenergic, enhancement sharpens visual spatial perception in humans. J Neurosci 2017;37(16):4405-15.

85. Ukai K, Fujishiro H, Iritani S, Ozaki N. Long-term efficacy of donepezil for relapse of visual hallucinations in patients with dementia with Lewy bodies. Psychogeriatrics. 2015;15(2):133-7.

86. Banerjee AK, Falkai PG, Savidge M. Visual hallucinations in the elderly associated with the use of levodopa. Postgrad Med J 1989;65(764):358-61.

87. Mattavelli G, Barvas E, Longo C, Zappini F, Ottaviani D, Malaguti MC, et al. Facial expressions recognition and discrimination in Parkinson's disease. J Neuropsychol 2020.

88. Coundouris SP, Adams AG, Grainger SA, Henry JD. Social perceptual function in parkinson's disease: a meta-analysis. Neurosci Biobehav Rev 2019;104:255-67.

89. Ho MW, Chien SH, Lu MK, Chen JC, Aoh Y, Chen CM, et al. Impairments in face discrimination and emotion recognition are related to aging and cognitive dysfunctions in Parkinson's disease with dementia. Sci Rep 2020;10(1):4367.

90. Kanwisher N, McDermott J, Chun MM. The fusiform face area: a module in human extrastriate cortex specialized for face perception. J Neurosci 1997;17(11):4302-11.
91. Cousins R, Hanley JR, Davies AD, Turnbull CJ, Playfer JR. Understanding memory for faces in Parkinson's disease: the role of configural processing. Neuropsychologia. 2000;38(6):837-47. https://doi.org/10.1016/s0028-3932(99)00133-5.

92. MacDonald AA, Seergobin KN, Owen AM, Tamjeedi R, Monchi $\mathrm{O}$, Ganjavi H, et al. Differential effects of Parkinson's disease and dopamine replacement on memory encoding and retrieval. PLoS One 2013;8(9):e74044.

93. Kotzbauer PT, Cairns NJ, Campbell MC, Willis AW, Racette BA, Tabbal SD, et al. Pathologic accumulation of alpha-synuclein and Abeta in Parkinson disease patients with dementia. Arch Neurol 2012;69(10):1326-31.

94. Guo Y, Xu W, Liu FT, Li JQ, Cao XP, Tan L, et al. Modifiable risk factors for cognitive impairment in Parkinson's disease: a systematic review and meta-analysis of prospective cohort studies. Mov Disord 2019;34(6):876-83.

95. Zhang Q, Kim YC, Narayanan NS. Disease-modifying therapeutic directions for Lewy-body dementias. Front Neurosci 2015;9:293.

96. Goodnick PJ, Goldstein BJ. Selective serotonin reuptake inhibitors in affective disorders-I. Basic pharmacology. J Psychopharmacol. 1998;12(3 Suppl B):S5-20.

97. Owens MJ, Morgan WN, Plott SJ, Nemeroff CB. Neurotransmitter receptor and transporter binding profile of antidepressants and their metabolites. J Pharmacol Exp Ther 1997;283(3):1305-22.

98. Andrade $\mathrm{C}$ Anticholinergic drug exposure and the risk of dementia: there is modest evidence for an association but not for causality. J Clin Psychiatry. 2019;80(4).

99. Wagg A, Dale M, Tretter R, Stow B, Compion G. Randomised, multicentre, placebo-controlled, double-blind crossover study investigating the effect of solifenacin and oxybutynin in elderly people with mild cognitive impairment: the SENIOR study. Eur Urol 2013;64(1):74-81.

100. Kim YJ, Tae BS, Bae JH. Cognitive function and urologic medications for lower urinary tract symptoms. Int Neurourol J 2020;24(3):231-40.

101. Peroutka SJ, Snyder SH. Antiemetics: neurotransmitter receptor binding predicts therapeutic actions. Lancet. 1982;1(8273):658-9.

102. Wallace DM, Wohlgemuth WK, Trotti LM, Amara AW, Malaty IA, Factor SA, et al. Practical evaluation and management of insomnia in Parkinson's disease: a review. Mov Disord Clin Pract 2020;7(3):250-66.

103. Cummings JL, Geldmacher D, Farlow M, Sabbagh M, Christensen D, Betz P. High-dose donepezil (23 mg/day) for the treatment of moderate and severe Alzheimer's disease: drug profile and clinical guidelines. CNS Neurosci Ther 2013;19(5):294301.

104. Kandiah N, Pai MC, Senanarong V, Looi I, Ampil E, Park KW, et al. Rivastigmine: the advantages of dual inhibition of acetylcholinesterase and butyrylcholinesterase and its role in subcortical vascular dementia and Parkinson's disease dementia. Clin Interv Aging 2017;12:697-707.

105. Emre M, Poewe W, De Deyn PP, Barone P, Kulisevsky J, Pourcher E, et al. Long-term safety of rivastigmine in Parkinson disease dementia: an open-label, randomized study. Clin Neuropharmacol 2014;37(1):9-16.

106. Devos D, Moreau C, Maltete D, Lefaucheur R, Kreisler A, Eusebio A, et al. Rivastigmine in apathetic but dementia and depression-free patients with Parkinson's disease: a double-blind, placebo-controlled, randomised clinical trial. J Neurol Neurosurg Psychiatry 2014;85(6):668-74.

107. Dubois B, Tolosa E, Katzenschlager R, Emre M, Lees AJ, Schumann G, et al. Donepezil in Parkinson's disease dementia: a randomized, double-blind efficacy and safety study. Mov Disord 2012;27(10):1230-8. 
108. Aarsland D, Laake K, Larsen JP, Janvin C. Donepezil for cognitive impairment in Parkinson's disease: a randomised controlled study. J Neurol Neurosurg Psychiatry 2002;72(6):708-12.

109. Ravina B, Putt M, Siderowf A, Farrar JT, Gillespie M, Crawley A, et al. Donepezil for dementia in Parkinson's disease: a randomised, double blind, placebo controlled, crossover study. J Neurol Neurosurg Psychiatry 2005;76(7):934-9.

110. Leroi I, Brandt J, Reich SG, Lyketsos CG, Grill S, Thompson R, et al. Randomized placebo-controlled trial of donepezil in cognitive impairment in Parkinson's disease. Int J Geriatr Psychiatry 2004;19(1):1-8

111. Mori E, Ikeda M, Kosaka K, Donepezil DLBSI. Donepezil for dementia with Lewy bodies: a randomized, placebo-controlled trial. Ann Neurol 2012;72(1):41-52.

112. Wang HF, Yu JT, Tang SW, Jiang T, Tan CC, Meng XF, et al. Efficacy and safety of cholinesterase inhibitors and memantine in cognitive impairment in Parkinson's disease, Parkinson's disease dementia, and dementia with Lewy bodies: systematic review with meta-analysis and trial sequential analysis. J Neurol Neurosurg Psychiatry 2015;86(2):135-43.

113. Mantri S, Fullard M, Gray SL, Weintraub D, Hubbard RA, Hennessy S, et al. Patterns of dementia treatment and frank prescribing errors in older adults with Parkinson disease. JAMA Neurol 2019;76(1):41-9.

114. Leroi I, Overshott R, Byrne EJ, Daniel E, Burns A. Randomized controlled trial of memantine in dementia associated with Parkinson's disease. Mov Disord 2009;24(8):1217-21.

115. Aarsland D, Ballard C, Walker Z, Bostrom F, Alves G, Kossakowski K, et al. Memantine in patients with Parkinson's disease dementia or dementia with Lewy bodies: a double-blind, placebo-controlled, multicentre trial. Lancet Neurol 2009;8(7): 613-8.

116. Emre M, Tsolaki M, Bonuccelli U, Destee A, Tolosa E, Kutzelnigg A, et al. Memantine for patients with Parkinson's disease dementia or dementia with Lewy bodies: a randomised, double-blind, placebo-controlled trial. Lancet Neurol 2010;9(10): 969-77.

117. Menendez-Gonzalez M, Calatayud MT, Blazquez-Menes B. Exacerbation of Lewy bodies dementia due to memantine. J Alzheimers Dis 2005;8(3):289-91.

118. Ridha BH, Josephs KA, Rossor MN. Delusions and hallucinations in dementia with Lewy bodies: worsening with memantine. Neurology. 2005;65(3):481-2.

119. Mamikonyan E, Xie SX, Melvin E, Weintraub D. Rivastigmine for mild cognitive impairment in Parkinson disease: a placebocontrolled study. Mov Disord 2015;30(7):912-8.

120. Olanow CW, Rascol O, Hauser R, Feigin PD, Jankovic J, Lang A, et al. A double-blind, delayed-start trial of rasagiline in Parkinson's disease. N Engl J Med 2009;361(13):1268-78.

121. Hanagasi HA, Gurvit H, Unsalan P, Horozoglu H, Tuncer N, Feyzioglu A, et al. The effects of rasagiline on cognitive deficits in Parkinson's disease patients without dementia: a randomized, double-blind, placebo-controlled, multicenter study. Mov Disord 2011;26(10):1851-8.

122. Weintraub D, Hauser RA, Elm JJ, Pagan F, Davis MD, Choudhry A, et al. Rasagiline for mild cognitive impairment in Parkinson's disease: a placebo-controlled trial. Mov Disord 2016;31(5):70914.

123. Hinson VK, Delambo A, Elm J, Turner T. A randomized clinical trial of atomoxetine for mild cognitive impairment in Parkinson's disease. Mov Disord Clin Pract 2017;4(3):416-23.

124. Krames ES, Hunter Peckham P, Rezai A, Aboelsaad F. Chapter 1 what is neuromodulation? In: Krames ES, Peckham PH, Rezai AR, editors. Neuromodulation. San Diego: Academic Press; 2009. p. 3-8.
125. Follett KA, Weaver FM, Stern M, Hur K, Harris CL, Luo P, et al. Pallidal versus subthalamic deep-brain stimulation for Parkinson's disease. N Engl J Med 2010;362(22):2077-91.

126. Deuschl G, Schade-Brittinger C, Krack P, Volkmann J, Schäfer H, Bötzel K, et al. A randomized trial of deep-brain stimulation for Parkinson's disease. N Engl J Med 2006;355(9):896-908.

127. Temel Y, Blokland A, Steinbusch HWM, Visser-Vandewalle V. The functional role of the subthalamic nucleus in cognitive and limbic circuits. Prog Neurobiol 2005;76(6):393-413.

128. Kelley R, Flouty O, Emmons EB, Kim Y, Kingyon J, Wessel JR, et al. A human prefrontal-subthalamic circuit for cognitive control. Brain. 2018;141(1):205-16.

129. Chen KH, Okerstrom KL, Kingyon JR, Anderson SW, Cavanagh JF, Narayanan NS. Startle habituation and midfrontal theta activity in Parkinson disease. J Cogn Neurosci 2016;28(12):1923-32. https://doi.org/10.1162/jocn_a_01012.

130. Singh A, Cole RC, Espinoza AI, Brown D, Cavanagh JF, Narayanan NS. Frontal theta and beta oscillations during lowerlimb movement in Parkinson's disease. Clin Neurophysiol 2020;131(3):694-702.

131. Singh A, Richardson SP, Narayanan N, Cavanagh JF. Mid-frontal theta activity is diminished during cognitive control in Parkinson's disease. Neuropsychologia. 2018;117:113-22.

132. Parker KL, Chen KH, Kingyon JR, Cavanagh JF, Narayanan NS. Medial frontal approximately 4-Hz activity in humans and rodents is attenuated in PD patients and in rodents with cortical dopamine depletion. J Neurophysiol 2015;114(2):1310-20.

133. Haynes WIA, Haber SN. The organization of prefrontalsubthalamic inputs in primates provides an anatomical substrate for both functional specificity and integration: implications for basal ganglia models and deep brain stimulation. J Neurosci 2013;33(11):4804-14.

134. Nambu A, Tokuno H, Takada M. Functional significance of the cortico-subthalamo-pallidal 'hyperdirect' pathway. Neurosci Res 2002;43(2):111-7.

135. Heo J-H, Lee K-M, Paek SH, Kim M-J, Lee J-Y, Kim J-Y, et al. The effects of bilateral subthalamic nucleus deep brain stimulation (STN DBS) on cognition in Parkinson disease. J Neurol Sci 2008;273(1-2):19-24.

136. Odekerken VJJ, Boel JA, Schmand BA, de Haan RJ, Figee M, van den Munckhof P, et al. GPi vs STN deep brain stimulation for Parkinson disease: three-year follow-up. Neurology. 2016;86(8): 755-61.

137. Freund HJ, Kuhn J, Lenartz D, Mai JK, Schnell T, Klosterkoetter J, Sturm V, et al. Cognitive functions in a patient with Parkinsondementia syndrome undergoing deep brain stimulation. (15383687 (Electronic)).

138. Leoutsakos JS, Yan H, Anderson WS, Asaad WF, Baltuch G, Burke A, et al. Deep Brain Stimulation Targeting the Fornix for Mild Alzheimer Dementia (the ADvance Trial): a two year followup including results of delayed activation. J Alzheimers Dis 2018;64(2):597-606.

139. Zavala B, Jang A, Trotta M, Lungu CI, Brown P, Zaghloul KA. Cognitive control involves theta power within trials and beta power across trials in the prefrontal-subthalamic network. Brain J Neurol 2018;141(12):3361-76.

140. Zavala B, Tan H, Ashkan K, Foltynie T, Limousin P, Zrinzo L, et al. Human subthalamic nucleus-medial frontal cortex theta phase coherence is involved in conflict and error related cortical monitoring. Neuroimage. 2016;137:178-87.

141. Scangos KW, Carter CS, Gurkoff G, Zhang L, Shahlaie K. A pilot study of subthalamic theta frequency deep brain stimulation for cognitive dysfunction in Parkinson's disease. Brain Stimul 2018;11(2):456-8. 
142. Wojtecki L, Elben S, Timmermann L, Reck C, Maarouf M, Jorgens S, et al. Modulation of human time processing by subthalamic deep brain stimulation. PLoS One. 2011;6(9).

143. Siebner HR, Mentschel C, Auer C, Conrad B. Repetitive transcranial magnetic stimulation has a beneficial effect on bradykinesia in Parkinson's disease. Neuroreport. 1999;10(3):589-94.

144. Boggio PS, Fregni F, Bermpohl F, Mansur CG, Rosa M, Rumi DO, et al. Effect of repetitive TMS and fluoxetine on cognitive function in patients with Parkinson's disease and concurrent depression. Mov Disord 2005;20(9):1178-84.

145. Cantello R, Tarletti R, Civardi C. Transcranial magnetic stimulation and Parkinson's disease. Brain Res Rev 2002;38(3):309-27.

146. Shin H-W, Youn YC, Chung SJ, Sohn YH. Effect of highfrequency repetitive transcranial magnetic stimulation on major depressive disorder in patients with Parkinson's disease. J Neurol 2016;263(7):1442-8.

147. Trung J, Hanganu A, Jobert S, Degroot C, Mejia-Constain B, Kibreab M, et al. Transcranial magnetic stimulation improves cognition over time in Parkinson's disease. Parkinsonism Relat Disord 2019;66:3-8.

148. Lawrence BJ, Gasson N, Bucks RS, Troeung L, Loftus AM. Cognitive training and noninvasive brain stimulation for cognition in Parkinson's disease: a meta-analysis. Neurorehabil Neural Repair 2017;31(7):597-608.

149. Reinhart RMG, Nguyen JA. Working memory revived in older adults by synchronizing rhythmic brain circuits. Nat Neurosci 2019;22(5):820-7.

150. Doruk D, Gray Z, Bravo GL, Pascual-Leone A, Fregni F. Effects of tDCS on executive function in Parkinson's disease. Neurosci Lett 2014;582:27-31.

151. Little S, Pogosyan A, Neal S, Zavala B, Zrinzo L, Hariz M, et al. Adaptive deep brain stimulation in advanced Parkinson disease. Ann Neurol 2013;74(3):449-57.

152. Beudel M, Brown P. Adaptive deep brain stimulation in Parkinson's disease. Parkinsonism Relat Disord 2016;22 Suppl 1:S123-6.

153. Parker KL, Chen KH, Kingyon JR, Cavanagh JF, Narayanan NS. Medial frontal $\sim 4-\mathrm{Hz}$ activity in humans and rodents is attenuated in PD patients and in rodents with cortical dopamine depletion. J Neurophysiol 2015;114(2):1310-20.

154. Anjum MF, Dasgupta S, Mudumbai R, Singh A, Cavanagh JF, Narayanan NS. Linear predictive coding distinguishes spectral EEG features of Parkinson's disease. Parkinsonism Relat Disord 2020;79:79-85.

155. Colcombe SJ, Kramer AF, Erickson KI, Scalf P, McAuley E, Cohen NJ, et al. Cardiovascular fitness, cortical plasticity, and aging. Proc Natl Acad Sci U S A 2004;101(9):3316-21.

156. Sink KM, Espeland MA, Castro CM, Church T, Cohen R, Dodson JA, et al. Effect of a 24-month physical activity intervention vs health education on cognitive outcomes in sedentary older adults: the LIFE Randomized Trial. JAMA. 2015;314(8):781-90.

157. Lautenschlager NT, Cox KL, Flicker L, Foster JK, van Bockxmeer FM, Xiao J, et al. Effect of physical activity on cognitive function in older adults at risk for Alzheimer disease: a randomized trial. JAMA. 2008;300(9):1027-37.

158. Smith PJ, Blumenthal JA, Hoffman BM, Cooper H, Strauman TA, Welsh-Bohmer K, et al. Aerobic exercise and neurocognitive performance: a meta-analytic review of randomized controlled trials. Psychosom Med 2010;72(3):239-52.

159. Uc EY, Doerschug KC, Magnotta V, Dawson JD, Thomsen TR, Kline JN, et al. Phase I/II randomized trial of aerobic exercise in Parkinson disease in a community setting. Neurology. 2014;83(5): 413-25.

160. David FJ, Robichaud JA, Leurgans SE, Poon C, Kohrt WM, Goldman JG, et al. Exercise improves cognition in Parkinson's disease: the PRET-PD randomized, clinical trial. Mov Disord 2015;30(12):1657-63.

161. Bechara A, Damasio H, Damasio AR. Emotion, decision making and the orbitofrontal cortex. Cereb Cortex 2000;10(3):295-307.

162. Beck JS, Beck JS. Cognitive Behavior Therapy: Basics and Beyond. 2nd ed. New York: Guilford Press; 2011. xix, 391 p. p.

163. Bernstein DA, Borkovec TD. Progressive Relaxation Training: a Manual for the Helping Professions. Champaign, Ill.: Research Press; 1973. viii, 66 p. p.

164. Pena J, Ibarretxe-Bilbao N, Garcia-Gorostiaga I, GomezBeldarrain MA, Diez-Cirarda M, Ojeda N. Improving functional disability and cognition in Parkinson disease: randomized controlled trial. Neurology. 2014;83(23):2167-74.

165. Leung IH, Walton CC, Hallock H, Lewis SJ, Valenzuela M, Lampit A. Cognitive training in Parkinson disease: a systematic review and meta-analysis. Neurology. 2015;85(21):1843-51.

166. Edwards JD, Hauser RA, O’Connor ML, Valdes EG, Zesiewicz TA, Uc EY. Randomized trial of cognitive speed of processing training in Parkinson disease. Neurology. 2013;81(15):1284-90.

167. Cerasa A, Gioia MC, Salsone M, Donzuso G, Chiriaco C, Realmuto S, et al. Neurofunctional correlates of attention rehabilitation in Parkinson's disease: an explorative study. Neurol Sci 2014;35(8):1173-80.

168. Orgeta V, McDonald KR, Poliakoff E, Hindle JV, Clare L, Leroi I. Cognitive training interventions for dementia and mild cognitive impairment in Parkinson's disease. Cochrane Database Syst Rev 2020;2:CD011961.

Publisher's Note Springer Nature remains neutral with regard to jurisdictional claims in published maps and institutional affiliations. 